\title{
Pathological changes after intravenous streptokinase treatment in eight patients with acute myocardial infarction
}

\author{
S GEOFFREY RICHARDSON, DEREK C ALLEN, PATRICIA MORTON, \\ J GERARD MURTAGH, MICHAEL E SCOTT, D BARRY O'KEEFFE
}

From the Cardiac Unit and Histopathology Department, Belfast City Hospital, Belfast

SUMMARY At necropsy five of eight patients (mean age 57 years) who died after intravenous streptokinase treatment for severe acute myocardial infarction (mean Peel index $=18$ ) were found to have a patent infarct related coronary artery. Coronary artery stenoses were caused by fibrofatty atheromatous plaques; there were no residual thrombi in the lumen or acute intimal lesions. Three of these infarcts were of partial thickness (less than two thirds wall width) with sparing of the outer third of the myocardium and subendocardial zones. In the other three patients the infarct related coronary arteries remained histologically closed with residual lumen thrombi and underlying intimal lesions. Two infarcts were transmural. Six of the eight infarcts were noticeably haemorrhagic. Myocardial haemorrhage was confined to areas of necrotic myocardium and did not affect viable regions.

These findings suggest that thrombus overlying a complex lesion may be more difficult to lyse than thrombus overlying a simple fibrofatty plaque. They also suggest that myocardial haemorrhage outside the infarct area, which might lead to cardiac rupture or delayed healing, does not usually occur.

There has been relatively little reported work on human cardiac pathology after thrombolytic treatment and several points are not clear. Myocardial haemorrhage may occur after coronary reperfusion. Although the weight of evidence suggests that this only occurs in areas of irreversibly damaged myocardium, fatal haemorrhagic myocardial infarction has been described after intracoronary streptokinase treatment. $^{12}$ It has also been suggested that the success of coronary artery recanalisation depends, in part, on the morphologic features of the coronary occlusion and that reperfusion after successful thrombolysis may lead to a different pattern of muscle fibre necrosis in the irreversibly injured infarct areas. ${ }^{3}$

The aims of this study were to characterise the changes in the myocardium after streptokinase treatment and to determine whether streptokinase treatment directly contributed to mortality in any patient. The patency of the infarct related coronary artery was examined in relation to the morphology of the

Requests for reprints to Dr S Geoffrey Richardson, Cardiac Unit, Belfast City Hospital, Lisburn Road, Belfast BT9 7AB.

Accepted for publication 2 February 1989 underlying coronary lesion and to the extent of myocardial damage.

\section{Patients and methods}

Over a 15 month period necropsies were performed on eight patients who died after receiving thrombolytic treatment for acute myocardial infarction. Patients less than 70 were treated with 1.5 million units of streptokinase intravenously if they had chest pain lasting $<6 \mathrm{~h}$, typical ST segment elevation of at least $2 \mathrm{~mm}$ in the precordial chest leads or $1 \mathrm{~mm}$ in the standard limb leads, evidence of severe myocardial infarction (Peel coronary prognostic index $>13^{4}$ ), and no specific contraindications to thrombolytic treatment or anticoagulation. Thirteen patients died in hospital after thrombolytic treatment. Consent for a necropsy was not given in five cases.

\section{PATHOLOGY}

A full necropsy was carried out on each patient within 30 hours after death. The hearts were weighed and the external surfaces inspected. The ascending aortic 
trunk was cut close to the valve ring and the coronary artery ostia were identified and inspected. The ostium of the infarct related main arterial trunk was cannulated with a 9 French gauge coronary catheter that was tied in place by means of a periarterial suture. The artery was injected with a solution of radiocontrast material under fluoroscopic imaging. Arterial stenoses and occlusions were identified and radiographic films were taken in different planes. The non-infarct arterial trunk was injected, and the injection medium was flushed out of the coronary arteries with physiological saline. The hearts were then fixed in formalin for $\mathbf{4 8}$ hours.

We used angiograms obtained after death to guide dissection; the coronary arteries were cut into serial transverse blocks every $2 \mathrm{~mm}$. Stenosed segments were removed and decalcified. Histological sections $(5 \mu \mathrm{m})$ were cut and examined throughout each block. The hearts were opened and inspected. Multiple transverse horizontal slices of the left ventricle were produced, in which the infarct appearance was noted and linear measurements of infarct size were made. Histological sections were stained with haematoxylin and eosin and the Martius scarlet blue technique. The severity of coronary artery stenosis was assessed by measuring the residual cross sectional luminal area as a percentage of the assumed original cross sectional area of the vessel (the area encircled by the internal elastic lamina). We measured the vessel diameters with an eyepiece graticule. ${ }^{5}$ The cross sectional area (A) was calculated from the maximum lumen diameter (D) and the minimum lumen diameter (d) by the formula: $\mathrm{A}=\pi(\mathrm{D} \times \mathrm{d}) / 4$ (this formula assumes an elliptical cross section).

\section{Results}

\section{MORTALITY DATA}

Six patients had an anterior wall infarction and one patient had an inferior wall infarction (table 1). In one patient there was evidence of combined anterior and inferior wall infarction. Myocardial infarction was assessed as severe in all patients at clinical presentation (mean Peel coronary prognostic index $=18$, range 14-21). At admission all patients had systemic hypotension and five had left ventricular failure (patients 3, 5, 6, 7, and 8). The mean time from onset of ischaemic chest pain to treatment with streptokinase was 1.8 hours (range 30 minutes to three hours). After streptokinase treatment cardiac failure persisted in five patients (patients $3,5,6,7$, and 8 ). Three patients (patients 1,2 , and 4 ) initially made a good recovery. In patients 1 and 4 recurrent ischaemic chest pain and electrocardiographic ST elevation suggested coronary reocclusion. Clinical deterioration and death followed. Patient 2 developed abdominal pain and refractory hypotension on the third week after streptokinase treatment. Necropsy confirmed the presence of mesenteric embolism.

Percutaneous transluminal coronary angioplasty of a lesion of the proximal left coronary artery was successfully performed on patient 5 two days after streptokinase treatment. Despite this intervention cardiac failure and hypotension persisted. This patient's clinical course was also complicated by gastrointestinal haemorrhage.

\section{PATHOLOGY}

The infarct related coronary artery was patent in five patients (table 2). All had severe atheromatous stenoses. In four patients the stenosis was caused by an uncomplicated, obstructive fibrofatty arterial plaque with no residual thrombus in the lumen or acute intimal lesion (fig 1). The fifth showed an intimal and medial longitudinal split capped by thrombus. This patient had coronary angioplasty after streptokinase treatment.

The infarct related coronary artery remained occluded in three cases. There was a complicated atheromatous stenosis in all three. An acute intimal lesion was associated with occlusive thrombus in the lumen (fig 2).

Haemorrhagic myocardial infarction was present in four of five patients with an open infarct related coronary artery (table 3 ). In three of these five

Table 1 Summary of clinical findings

\begin{tabular}{|c|c|c|c|c|c|c|c|}
\hline $\begin{array}{l}\text { Case } \\
\text { no }\end{array}$ & $\begin{array}{l}\text { Age } \\
\text { sex }\end{array}$ & and & $\begin{array}{l}\text { Infarct } \\
\text { site }\end{array}$ & $\begin{array}{l}\text { Peel } \\
\text { index }\end{array}$ & $\begin{array}{l}\text { Time to } \\
\text { treatment }(h)\end{array}$ & Clinical course & $\begin{array}{l}\text { Time of death } \\
\text { (day) }\end{array}$ \\
\hline $\begin{array}{l}1 \\
2 \\
3 \\
4 \\
5\end{array}$ & $\begin{array}{l}50 \\
67 \\
67 \\
58 \\
55\end{array}$ & $\begin{array}{l}\mathbf{M} \\
\mathbf{M} \\
\mathbf{M} \\
\mathbf{F} \\
\mathbf{M}\end{array}$ & $\begin{array}{l}\mathbf{A} \\
\mathbf{A} \\
\mathbf{A} \\
\mathbf{A} / \mathbf{I} \\
\mathbf{A}\end{array}$ & $\begin{array}{l}14 \\
21 \\
17 \\
15 \\
20\end{array}$ & $\begin{array}{l}1 \cdot 5 \\
1 \cdot 7 \\
3 \cdot 0 \\
1 \cdot 5 \\
3 \cdot 0\end{array}$ & $\begin{array}{l}\text { Reocclusion day } 5 \\
\text { Mesenteric embolism } \\
\text { Refractory cardiac failure } \\
\text { Reocclusion day } 3 \\
\text { Progressive cardiac failure plus } \\
\quad \text { gastrointestinal bleeding }\end{array}$ & $\begin{array}{r}5 \\
21 \\
4 \\
3 \\
6\end{array}$ \\
\hline $\begin{array}{l}6 \\
7 \\
8\end{array}$ & $\begin{array}{l}62 \\
40 \\
49\end{array}$ & $\begin{array}{l}\mathbf{M} \\
\mathbf{M}\end{array}$ & $\begin{array}{l}\text { A } \\
\text { A } \\
\text { I }\end{array}$ & $\begin{array}{l}18 \\
18 \\
20\end{array}$ & $\begin{array}{l}2 \cdot 0 \\
2 \cdot 5 \\
0 \cdot 5\end{array}$ & $\begin{array}{l}\text { Refractory cardiac failure } \\
\text { Refractory cardiac failure } \\
\text { Refractory cardiac failure }\end{array}$ & $\begin{array}{r}6 \\
10 \\
8\end{array}$ \\
\hline
\end{tabular}

$A$, anterior; 1 , inferior. 
Table 2 Pathological characteristics of the infarct related coronary artery

\begin{tabular}{|c|c|c|c|c|c|c|}
\hline \multirow[b]{2}{*}{ Case no } & \multirow[b]{2}{*}{ Infarct site } & \multicolumn{5}{|c|}{ Infarct artery } \\
\hline & & Patency ${ }^{\star}$ & Site & Stenosis (\%) & Plaque & Thrombus \\
\hline $\begin{array}{l}1 \\
2 \\
3 \\
4 \\
5 \\
6 \\
7 \\
8\end{array}$ & $\begin{array}{l}\mathbf{A} \\
\mathbf{A} \\
\mathbf{A} \\
\mathbf{A} / \mathbf{I} \\
\mathbf{A} \\
\mathbf{A} \\
\mathbf{A} \\
\mathbf{I}\end{array}$ & $\begin{array}{l}+ \\
+ \\
+ \\
+ \\
+ \\
- \\
-\end{array}$ & $\begin{array}{l}\text { LAD } \\
\text { LMS } \\
\text { LAD } \\
\text { LAD/RCA } \\
\text { LAD } \\
\text { LAD } \\
\text { LAD } \\
\text { RCA }\end{array}$ & $\begin{array}{l}91 \\
80 \\
80 \\
78 \\
78 \\
98 \\
90 \\
97\end{array}$ & $\begin{array}{l}\text { Fibrous } \\
\text { Fibrous } \\
\text { Fibrous } \\
\text { Fibrous } \\
\text { Rupture } \\
\text { Rupture } \\
\text { Rupture } \\
\text { Rupture }\end{array}$ & $\begin{array}{l}- \\
- \\
- \\
+ \\
+ \\
+ \\
+\end{array}$ \\
\hline
\end{tabular}

ॠInfarct artery: +, open; - closed.

LMS, left main stem; LAD, left anterior descending artery; RCA, right coronary artery.

patients myocardial infarction was of partial wall thickness (fig 3). One case showed a transmural myocardial infarction and one a mixed picture with areas of both partial thickness and transmural myocardial infarction.

Two of the three patients with an occluded infarct related artery were associated with transmural myocardial infarction and one with a partial thickness infarct (table 3).

Histological examination confirmed the haemor- rhagic nature of the infarcts. There were abundant $\stackrel{9}{9}$ aggregates of red blood cells in the interstitiumir between necrotic myofibres. This interstitial $\omega_{0}$ haemorrhage was associated with necrosis of the microvasculature. Haemorrhage was not present in 5 viable muscle. Partial thickness myocardial infarcts were characterised by preservation of a narrow subendocardial zone and the outer one third of the myocardium. In two patients, vessels containing $\vec{\bullet}$ small embolic thrombi were seen in the myocardium.

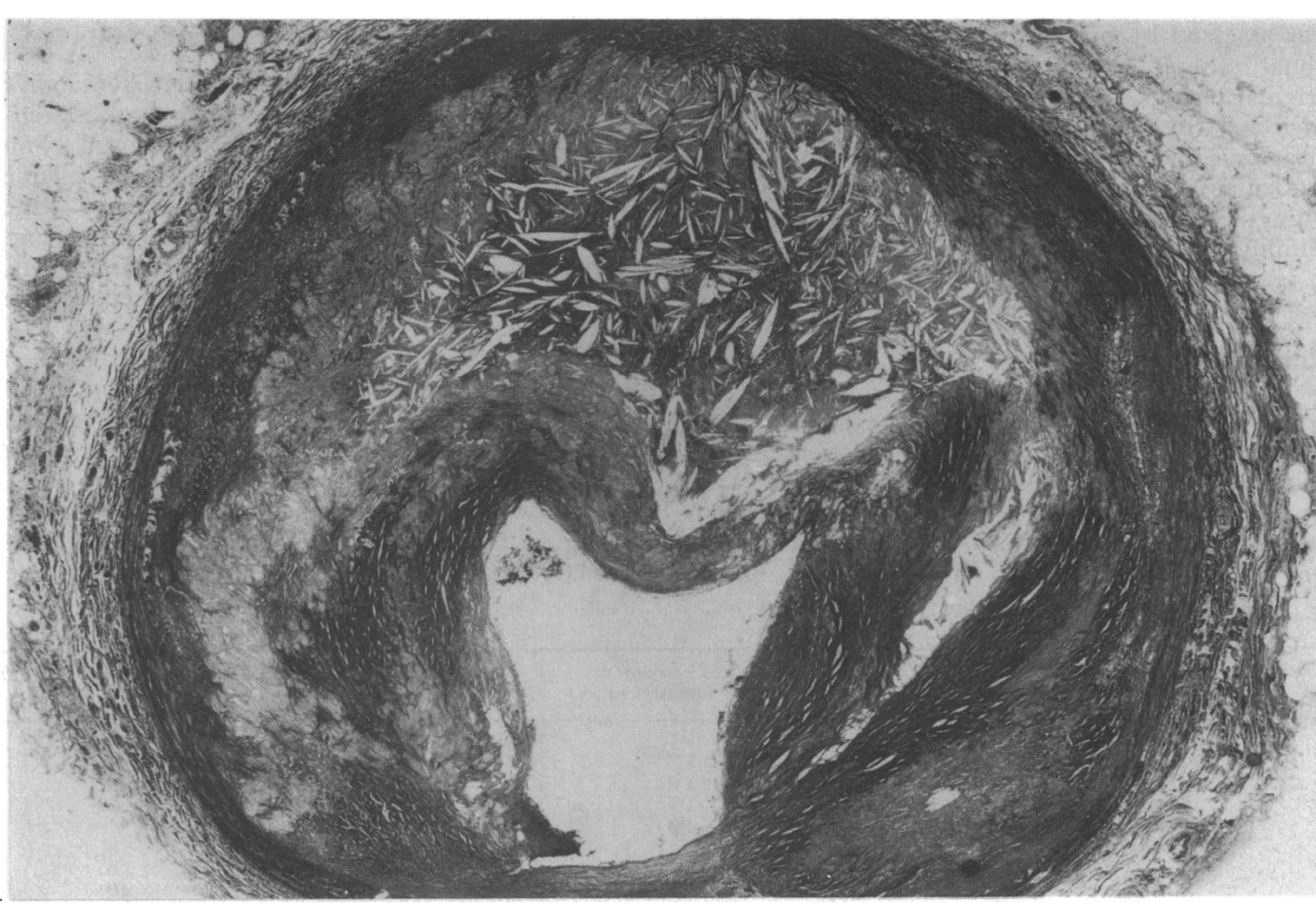

Fig 1 The left anterior descending artery in patient 1 was stenosed by a fibrofatty atheromatous plaque. The lumen was patent and the intima intact. Martius scarlet blue (original magnification, $\times 40$ ). 


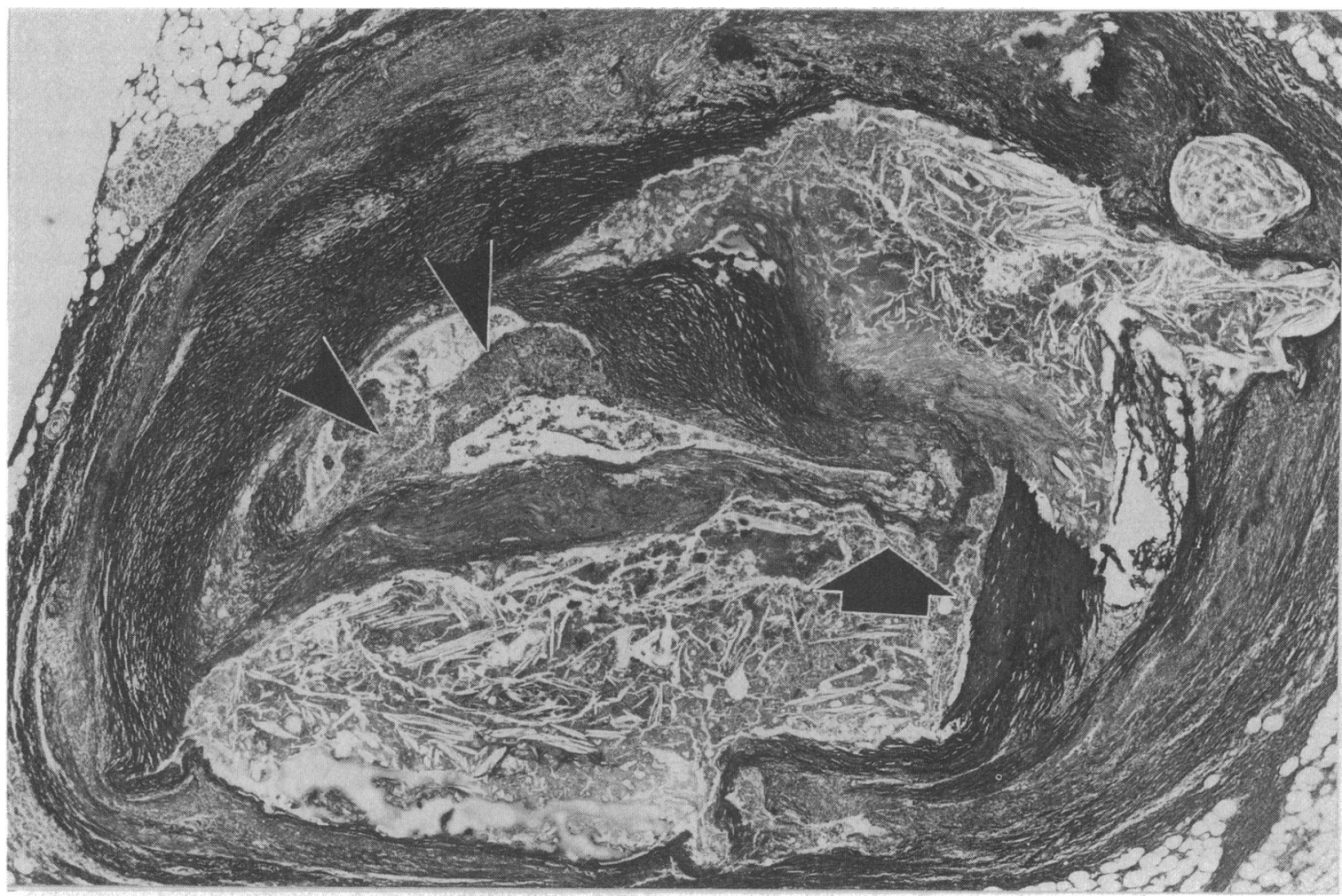

Fig 2 The left anterior descending coronary artery in patient 7 was stenosed by a ruptured plaque with an intimal lesion (arrow) and resultant lumen thrombus (arrowheads). Martius scarlet blue (original magnification, $\times 32$ ).

These thrombi probably originated from the fragmenting proximal obstructive thrombus (fig 4).

\section{Discussion}

The potential reduction of myocardial infarct size by thrombolysis and other treatments has been the subject of much interest in recent years. ${ }^{6}$ Clinical trials have shown both an improvement in hospital mortality $^{7}$ and left ventricular function ${ }^{8}$ after intravenous streptokinase treatment. Histopathological evidence of myocardial salvage after coronary reperfusion has mainly come from experimental coronary reperfusion in $\operatorname{dogs}^{910}$ and there has been relatively little published work in human beings. This experimental work has shown that a wavefront of ischaemic necrosis progresses from subendocardial myocardium to subepicardial myocardium over a

Table 3 Macroscopic and histopathological results

\begin{tabular}{|c|c|c|c|c|c|c|c|}
\hline \multirow[b]{2}{*}{ Case no } & \multirow[b]{2}{*}{ Infarct site } & \multirow[b]{2}{*}{ Patency $^{\star}$} & \multicolumn{5}{|l|}{ Infarct } \\
\hline & & & Area $\left(\mathrm{cm}^{2}\right)$ & $C N$ & $C B N$ & $H I$ & Thicknesst \\
\hline $\begin{array}{l}1 \\
2 \\
3 \\
4 \\
5 \\
6 \\
7 \\
8\end{array}$ & $\begin{array}{l}\mathbf{A} \\
\mathbf{A} \\
\mathbf{A} \\
\mathbf{A} / \mathbf{I} \\
\mathbf{A} \\
\mathbf{A} \\
\mathbf{A} \\
\mathbf{I}\end{array}$ & $\begin{array}{l}+ \\
+ \\
+ \\
+ \\
+ \\
- \\
-\end{array}$ & $\begin{array}{l}35 \\
46 \\
42 \\
15 / 6 \\
40 \\
56 \\
64 \\
18\end{array}$ & $\begin{array}{l}+ \\
+ \\
+ \\
+ \\
+ \\
+ \\
++ \\
+\end{array}$ & $\begin{array}{l}+ \\
+ \\
+ \\
- \\
++ \\
+ \\
++\end{array}$ & $\begin{array}{l}+ \\
+ \\
+ \\
- \\
+ \\
+ \\
+ \\
-\end{array}$ & $\begin{array}{l}\text { Partial } \\
\text { Partial } \\
\text { Transmural } \\
\text { Partial } \\
\text { Mixed } \\
\text { Transmural } \\
\text { Transmural } \\
\text { Partial }\end{array}$ \\
\hline
\end{tabular}

^Patency of the infarct artery $(+$, open; - , closed).

+ Extent of myocardial wall necrosis.

$\mathrm{CN}$, coagulative necrosis; CBN, contraction band necrosis; $\mathrm{HI}$, haemorrhagic infarction $(+$, haemorrhage present). 


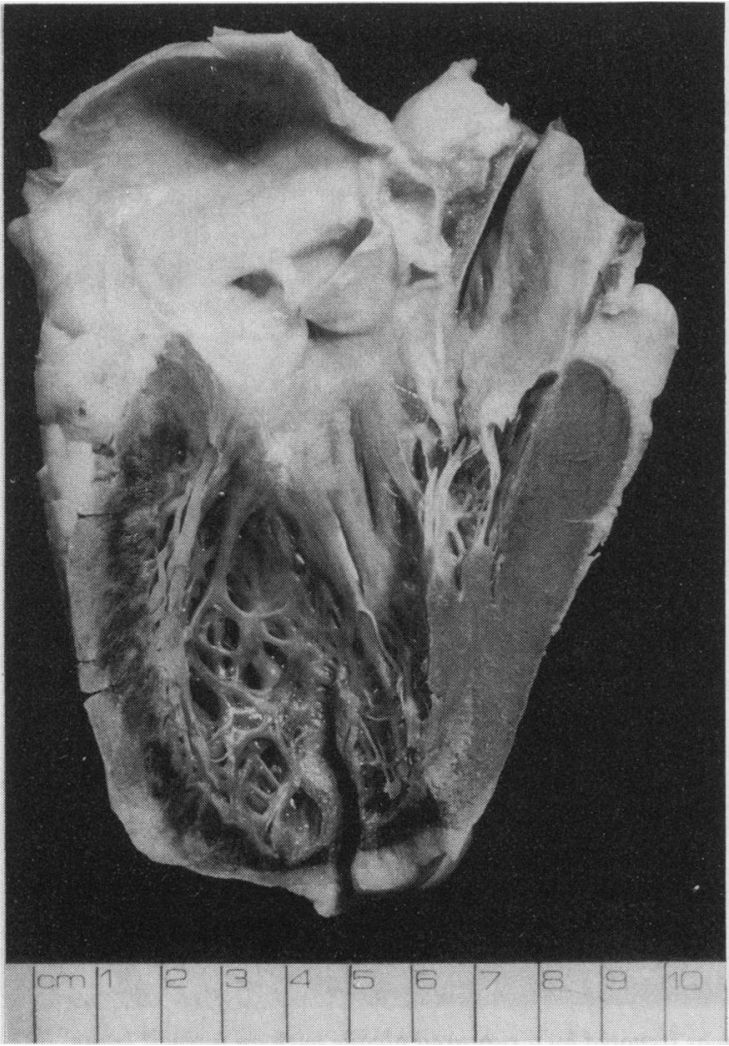

Fig 3 A case of successful reperfusion in patient 1. The infarct was noticeably haemorrhagic and of partial wall thickness.

period of several hours. Coronary reperfusion after release of the arterial ligatures halted the progression of this ischaemic wavefront, with salvage of the subepicardial myocardium. The extent of myocardial necrosis was related to the duration of coronary occlusion.

The results of the present study showed a trend towards the occurrence of partial thickness infarction in patients with an open infarct related coronary artery, and transmural infarction in patients with a closed infarct related coronary artery. None the less, we cannot reach any direct conclusions about myocardial salvage after streptokinase treatment. The number of cases examined was small and neither the degree of collateral circulation nor the size of the infarct bed at risk could be adequately assessed. Rentrop et al reported on 10 patients who had aortocoronary bypass grafting after intracoronary streptokinase treatment. ${ }^{11}$ Intraoperative inspection showed that the bulk of the reperfused myocardium was viable, and biopsy specimens from three patients showed damage only in the subendocardial region.

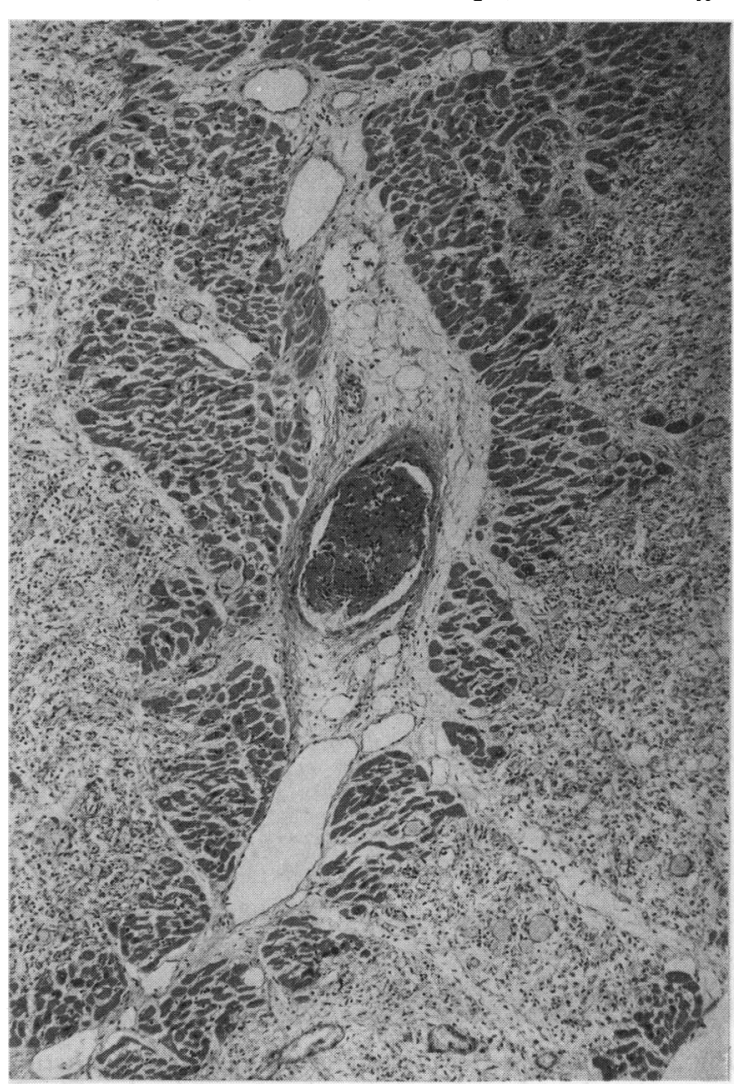

Fig 4 A surviving zone of perivascular myofibres. The central intramyocardial vessel contained a small embolic thrombus originating from the proximal fragmenting occlusion. Haematoxylin and eosin (original magnification, $\times 96)$.

In partial thickness myocardial infarcts Mattfeldt et al described the presence of contraction band necrosis due to aggregation of myofibre sarcomeres caused by reperfusion of irreversibly damaged myocytes. $^{3}$ This is different from the usual coagulative necrosis seen in the myocardium after permanent coronary occlusion. Contraction band necrosis was seen in the present study but also occurred in two of the three patients with a persistently occluded infarct related coronary artery as well as in four of the five patients with an open infarct related coronary artery. This suggests that contraction band necrosis is not solely a consequence of myocardial reperfusion.

The success of coronary artery recanalisation has been related to the complexity of the atheromatous occlusion. ${ }^{3}$ In this study, four of the five patients with a patent infarct related coronary artery had a simple fibrofatty plaque. In the fifth patient a simple lesion may have been complicated by postinfarction coron- 
ary angioplasty. In contrast, a complicated atheromatous stenosis with an acute intimal lesion was shown in all three patients with persistent coronary artery occlusion. This suggests that thrombus associated with a non-complicated lesion may be more easily lysed than thrombus overlying a complex mural lesion. The ease of clot dissolution, however, may also be related to the degree of atheromatous stenosis, which was greater in the complex lesions.

Terrosu $e t$ al studied the angiographic appearance of the coronary arteries during successful thrombolytic treatment. ${ }^{12}$ They found that total coronary occlusion was followed by the restoration of blood flow but with intraluminal filling defects and delayed distal flow possibly due to microembolism. We found intramyocardial microembolism in two of our patients. It is possible that microembolism may limit the benefits of thrombolysis by reducing blood flow through the distal coronary circulation.

The association between streptokinase treatment and haemorrhagic myocardial infarction has previously been noted and has even been held to be responsible for myocardial rupture. ${ }^{12}$ Haemorrhagic infarction was seen in six of our patients. Haemorrhage occurred into areas of myocardial necrosis and did not extend beyond the infarct into viable myocardium. The presence of infarct haemorrhage was not obviously responsible for complications in our study. This supports the results of experimental studies in dogs. These indicated that reperfusion haemorrhage occurs as a result of the microvascular damage that follows and it is never greater than the extent of myocardial necrosis. ${ }^{1314}$ Whether myocardial haemorrhage has any long term deleterious clinical effects remains uncertain. One encouraging report has shown that collagen formation is not delayed in haemorrhagic reperfused myocardial infarcts in dogs..$^{15}$

Swelling, degeneration, and separation of endothelial cells may lead to microvascular obstruction and the "no-reflow" effect after reperfusion. ${ }^{16}$ This may have been important in patient 3 who had a transmural infarct despite a patent infarct related coronary artery.

Myocardial haemorrhage was common after coronary reperfusion but occurred into areas of already irreversibly damaged myocardium and did not contribute to the death of any patient. The success of coronary artery reperfusion may be related to the complexity and degree of the underlying atheromatous lesion.

\section{References}

1 Mathey DG, Schofer J, Kuck K-H, Beil U, Klöppel G. Transmural, haemorrhagic myocardial infarction after intracoronary streptokinase. Clinical, angiographic, and necropsy findings. Br Heart $J$ 1982;48: 546-51.

2 Yasuno M, Endo S, Takahashi M, et al. Angiographic and pathologic evidence of haemorrhage into the myocardium after coronary reperfusion. Angiology 1984;35:797-801.

3 Mattfeldt T, Schwarz F, Schuler G, Hofmann M, Kubler W. Necropsy evaluation in seven patients with evolving acute myocardial infarction treated with thrombolytic therapy. Am J Cardiol 1984; 54:530-4.

4 Peel AAF, Semple T, Wang I, Lancaster WM, Dall JLG. A coronary prognostic index for grading the severity of infarction. Br Heart J 1962;24:745-60.

5 Falk E. Plaque rupture with severe pre-existing stenosis precipitating coronary thrombosis. Characteristics of coronary atherosclerotic plaques underlying fatal occlusive thrombi. Br Heart J 1983;50:127-34.

6 Kübler W, Doorey A. Reduction of infarct size. An attractive concept: useful-or possible-in humans? Br Heart J 1985;53:5-8.

7 Gruppo Italiano per lo Studio della streptochinasi nell'infarto miocardico. Effectiveness of intravenous thrombolytic treatment in acute myocardial infarction. Lancet 1986; $1397-401$.

8 The ISAM Study Group. A prospective trial of intravenous streptokinase in acute myocardial infarction (ISAM). Mortality, morbidity, and infarct size at 21 days. $N$ Engl J Med 1986;314:1465-71.

9 Reimer KA, Lowe JE, Rasmussen MM, Jennings RB. The wavefront phenomenon of ischaemic cell death. 1. Myocardial infarct size vs duration of coronary occlusion in dogs. Circulation 1977;56:786-94.

10 Jennings RB, Reimer KA. Factors involved in salvaging ischaemic myocardium: effect of reperfusion of arterial blood. Circulation 1983;68(suppl I):25-36.

11 Rentrop P, Blanke H, Karsch KR, et al. Effects of nonsurgical coronary reperfusion on the left ventricle in human subjects compared with conventional treatment. Study of 18 patients with acute myocardial infarction treated with intracoronary infusion of streptokinase. Am J Cardiol 1982;49:1-8.

12 Terrosu P, Ibba GV, Contini GM, Franceschino V. Angiographic features of the coronary arteries during intracoronary thrombolysis. $\mathrm{Br}$ Heart $J$ 1984;52: $154-63$.

13 Kloner RA, Rude RE, Carison N, Maroko PR, DeBoer LWV, Braunwald E. Ultrastructural evidence of microvascular damage and myocardial cell injury after coronary artery occlusion: which comes first? Circulation 1980;62:945-52.

14 Fishbein MC, Y-Rit J, Lando Y, Kanmatsuse K, Mercier JC, Ganz W. The relationship of vascular injury and myocardial haemorrhage to necrosis after reperfusion. Circulation 1980;62:1274-9.

15 Roberts CS, Schoen FJ, Kloner RA. Effect of coronary reperfusion on myocardial haemorrhage and infarct healing. Am J Cardiol 1983;52:610-4.

16 Hellstrom HR. Coronary artery stasis after induced myocardial infarction in the dog. Cardiovasc Res 1971;5:371-5. 